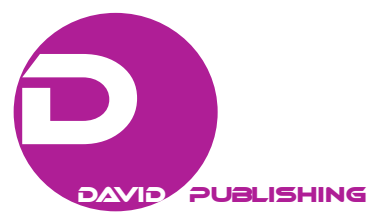

\title{
Accessible Tourism in Rome
}

\author{
Valeria Cocco, Marco Brogna \\ Dipartimento Memotef, La Sapienza University, MEMOTEF, Via del Castro Laurenziano, Italy
}

\begin{abstract}
The topics of inclusion and disability are currently discussed in modern society. In particular, the concept of accessibility draws a wide range of attention legislation, architecture and tourism. Accessible tourism is a quality perspective of tourism, and it provides a panorama of change and evolution. The paper, which focuses on the city of Rome, analyzes the advantages and criticisms of these "forgotten" and underestimated market niches. Information, transports, space distribution, and safety are involved in the development of the accessible destination. The paper opens a reflection about the opportunity and the perspective of improving a quality and accessible tourism in the Eternal City.
\end{abstract}

Keywords: accessible tourism, quality, barriers, inclusion, development.

\section{Advantages and Criticisms of a "Forgotten" Tourism Sector}

From a territorial point of view, accessibility is the ability of an environment or service to be easily accessed by any type of user. The instrument of accessibility naturally affects location, use and enjoyment of a territory, as well as to sensitize, for the effect, the development of reference structures and infrastructures.

It is possible to contextualize accessibility into the field of social tourism. In fact, accessible tourism is specifically addressed to tourists with disabilities or special needs: people with permanent or temporary disabilities, asthma, allergies, intolerances, etc. and it guarantees an easy and safe access to venues, facilities and points of interest, such as hotels, museums and restaurants. Accessible tourism is also called tourism for all. In fact, everyone can benefit from accessible infrastructures and venues (English Tourism Council, 2000; Shaw \& Coles, 2004). Elderly people, families with strollers or even people carrying heavy luggage can benefit from improved access. Accessible tourism is used to define a strand of tourism that takes care and protects disadvantaged people and prevents various forms of social discomfort. At the same time, it is inclusive, for example, because accessible tourism facilitates access to everyone. For this reason, it is defined as tourism for all.

Infrastructures and venues able to extend access to disabled people can be used by everyone. This means that investing in this sector does not limit the development of the tourism market, but rather enhances and increases it.

Accessible tourism is careful of all needs. It is functional, welcoming and open to everyone. It allows all the people to enjoy holiday and leisure activities in a safe and carefree environment. In a nutshell, it is quality tourism. The degree of accessibility can become a tool for measuring the quality of life within a given territory.

Accessibility is an essential element for tourism growth, as well as universal access to culture and travel and a deterrent to isolation. Travel provides opportunities for business as well as leisure activities. Travel

Valeria Cocco, PhD student, Dipartimento Memotef, Università La Sapienza; research field(s): economic geography . 
stimulates the development of human relationships, cultural enrichment and knowledge. It is an efficient instrument to break down obstacles and a trigger to economic and social grow th (Cocco \& Emberti Gialloreti, 2016, p. 48). The travel experience, from a tourist point of view, is a great and unique opportunity to learn and meet new cultures, to test and enrich one's own spirits and encourages personal growth.

For companies and business people, accessible tourism is a great prospect in terms of work, supply, competitiveness and economic benefits (Brogna, 2015). Accessibility involves the tourism industry in its entirety, from transport to cultural initiatives, from hotels to museums and creates growth opportunities for all economic actors and operators. In other words, it is an element to improve the quality of a destination.

It is a precious resource for tourism market and a valuable contribution to the development of local economies. In fact, accessible tourism not only deals with the universal principles enshrined in the Convention on the Rights of Persons with Disabilities, but it is above all an "intelligent, far-sighted, business investment".

Strengthening the link between the territory and the inclusive and social focus of entrepreneurship and, in particular, of the tourism sector, we can find the engine of a firmer development and the pillar of a culture of renewal.

\section{Accessible Destination}

In the tourist field, the motivation of the holiday is the key element on which the offer is built and, consequently, where communication and marketing actions are oriented (Aa. Vv., 2009). Tourists choose their destination according to their interests such as culture, religion, food and wine or sports, to cite some examples. In the context of accessible tourism, the travel motivation is the same, just as in the case of alternative tourist destinations such as France or Italy, the more safe and comfortable destination, the accessible one - will be preferred to another that does not have the same high-quality accessibility standards. This emphasizes the fluid and dynamic nature of tourism, and the necessity of a continuous renewal for high-quality destinations. A tourist destination must be an integrated system of attractions and facilities (Dredge \& Jenkins, 2003, p. 392), and provide resources to travelers in order to enjoy the destination so much, that they want to return. An accessible environment must be pleasant and functional; structured in such a way so as to provide comprehensible information and attention to the distribution of spaces, while ensuring the general conditions of safety and health. In fact, a successful tourist destination depends on implementing specific marketing strategies. A barrier-free destination meets the needs of people with disabilities. Customer satisfaction is one of the marketing levers for the creation of a successful destination's image. Moreover, an accessible tourist area should be structured to provide comprehensible information to everybody. At the same time, it should also provide careful, safe and healthy distribution of space. Accessibility enriches territories and creates useful services for everyone, so it proves the quality of the destination, for both citizens and businesses. It is a valuable resource for tourism and an effective contribution to the local economic development. These factors can make accessibility an essential element for the grow th of tourism, as well as to realize the universal right of accessibility of culture and travelling.

\section{Barriers-Free Environments}

The experience of traveling as a knowledge of new realities and an opportunity for personal growth is now adays considered a social right as well as a consoled habit. Unfortunately, people with disabilities are often excluded when supply systems are not tailored to their specific needs. The obstacles to easy access are 
characterized by the presence of architectural and cultural barriers. For that reason, in the architectural world, it has drawn attention to physical accessibility. The abolition of architectural barriers is now a topic on the agenda in the media as well as legislation. However, the guidelines provided to tourist actors are scarce with regard to the recognition of architectural barriers, whether they are visible or invisible. Therefore, the knowledge of the accessibility concept in the area remains marginal. To ensure a fully accessible tourist supply it is essential to recognize and distinguish the needs of people with disabilities. In the common imagination, disabled people are wheelchair people, while there are many invisible disabilities. Disability includes a variety of situations (Buono \& Zagara, 2003, p. 124). The World Health Organization classifies the various types of disability, distinguishing in: motor, cognitive, auditory and visual disability. An accessible place - by place we mean, in addition to the set of structures and infrastructures, also the whole transport and the virtual services - is a space for integration that is usable by everyone, not a space for marginalizing people with special needs. The venues must be welcoming, barrier-free, and usable anywhere in complete autonomy. An accessible design of the venues must meet certain criteria and technical requirements (Aslaksen, Bergh, Bringa \& Heggem, 1997), and in some cases, it may be a necessary process of awareness through staff training. This contributes to guarantee of sensitive and complete service. It also allows the service provider to identify access problems and to propose improvements. Another critical factor to consider is about horizontal mobility and the need of overcoming distances. So, it is proper to consider the dimensional characteristics and the way of access between the various functional areas of the structures; the dimensions and characteristics of the doors and access gates and the arrangement of the furnishings. Furniture is an element not to be underestimated. It is often the interior design that is not very functional and becomes an obstacle for those who have physical discomforts (Rota \& Rusconi 1996; Aslaksen, Bergh, Bringa, Heggem, 1997; Picone, 2004).

Another critical factor is the vertical mobility overcoming the layers. It concerns the easy access to the different services of the structure that are not located on the ground floor, but in other layers. Even a few stairs are a very serious obstacle for wheelchair people, as well as the slope of ramps. A non-speaking lift or the lack of braille signs are an obstacle for blind people. The presence of architectural barriers depends also on the time required and the high costs to be incurred to be removed or modified. In fact, generally the commitment and investment in structures without barriers are linked to the requirements of the law (Del Zanna, 1995; Darcy \& Dickson, 2009).

Sometimes structural changes are not enough for a complete accessibility of a place, so it is required to break down cultural barriers as well. Often gumption is not enough, and it becomes necessary for staff training to interact with guests in the best way. Staff training is of great importance for the dissemination of knowledge, skills and abilities necessary to cope with the different situation's difficulties.

\section{Accessible Tourism from a Business Perspective}

Accessible tourism is a great prospect for tour operators and companies in terms of competitiveness and economic benefits. It is evident that identifying a well-defined market target can be a difficult task. According to the statistics (European Commission, 2013), the number of accessible tourism destinations is constantly increasing. There is an increasing number of people with disabilities and the elderly in EU and extra-EU countries, as well as travelers over 65 years of age. The constant aging of the population moves into a grow th of the accessible market, for which a large part of tourists with special needs, is represented by the elderly people. Thus, if we consider the fact that tourists with special needs prefer not to travel alone, the number is still 
increasing. Doxa data display the number of families with special needs on holiday in 2015 ; there were 4.6 million families - a total 10 million people. Tourists with special needs, due to their limited autonomy, generally travel accompanied by relatives, friends or personal assistants. This means that the presence of helpers creates a multiplicative effect. In other words, the economic impact on the Italian GDP is 11.7 billion of Euros. Tourism for all also acquires a strong relevance for the development of domestic tourism, since people with special needs, especially the elderly ones, generally have a low propensity to travel abroad not to face greater barriers.

For this reason, accessible tourism tends to favor the development of the national tourism industry and thus develops the entire sector of the local area (Buhalis, Darcy, Ambrose, 2005). Tourists with special needs usually carry out more than one vacation a year, even during low season, or often they prefer to travel in low season because it is easier to stay and visit tourist sites in uncrowded places. In terms of supply, accessible tourism provides an intelligent solution to the seasonality through greater use of the infrastructure and a positive economic outlook for operators in the sector (Burnett \& Bender Baker, 2001; Eichhorn \& Buhalis, 2007).

The benefits deriving from accessible tourism, in fact, are for everyone, primarily encouraging local communities.

Moreover, if the accessible services offered meet the demand, there is an increase in the intensity of travel, frequency of travel and increase in the daily expenditure of tourists with specific needs, generating a process of increase not only in the quality of the offer for all guests, but also for the operators' economic income.

The more accessible the place is, the less investment is needed to be spent. As in a pyramid, tourism service providers invest in accessibility if they expect profits to be higher than the investments. The clear economic development perspectives - even if sometimes it is underestimated - lead to high revenues into the tourist sector.

Considering a tourist destination, some factors such as the accessibility of the destination and the presence of accessible services, the availability of operators, the availability of money, the interest of the vacation, will influence the economic decisions, as well as the economic returns. The competitive advantage of companies is realized when intangible resources are valued by balancing the interests of consumers with the company's ability to meet the needs of market and profit. Tourism spending has an effect on the income of companies in a region, bringing an immediate advantage to those operating in direct contact with tourists (i.e., accommodation, catering, travel agencies, etc.) and, indirectly, all those providing the first intermediate goods and services. Accessible tourism is a business opportunity. However, there is a lack of coordination, particularly between the public and private sectors. Building an accessible business opportunity is a positive approach to a strategy for a responsible business plan. It allows those with special needs to be able to meet on the market quality tourism proposals tailored to their needs and desires. Accessibility is not to be considered as a feature for disabled guests, but as an extra service for comfort and quality, or as a marketing and advertising strategy. So, we need to start looking at disability not as diversity, but as a value. Today, in fact, the accessible tourism market is still struggling to develop, due to the inaccessibility of one or more components of the product chain. Nevertheless, the interest of tour operators in this segment is constantly growing. Investing in the accessible tourism sector is therefore not only a question of ethics and morality, but rather a market strategy that tends to incorporate even that "partially forgotten" market niche and increase the quality of services and products offered for all. 


\section{Overview on Rome}

Rome is an important crossroads of culture, history and art. It is one of the most important tourist destinations. From the point of view of people with special needs, Rome is a huge "architectural barrier."

Too often the historical character of the eternal city is used as a justification for the scarce accessibility of infrastructures, transport and tourist services. This represents the first barrier that the city of Rome erects in front of the possibility of a tourism for all. It almost seems that territorial morphology is becoming an excuse to not break down barriers. Thanks to the main pillars of the accessible holiday, it is possible to evaluate the level of accessibility of the city of Rome. The main ingredients to create an accessible city belong to the physical and cultural accessibility of venues and services used by tourists. As in the figure below, the main ingredients for the creation of an accessible holiday are mobility, information and communication, services and experiences.

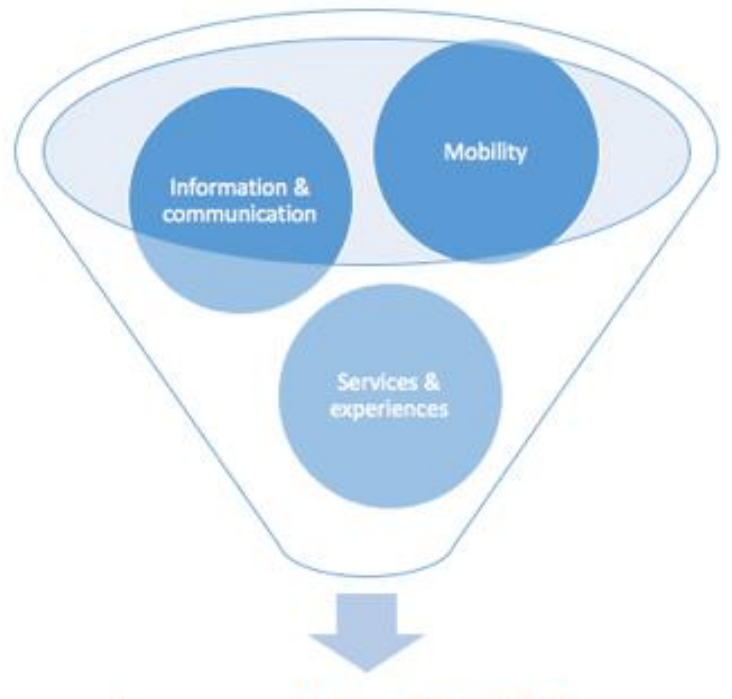

\section{Accessible Holiday}

Figure 1. Ingredients of an accessible holiday - own processing.

Focusing on the city of Rome, "Mobility" is the most critical aspect in accessibility. Public transport is not efficient, and not equipped with accessible systems for the needs of people. Road conditions are critical, especially in the center of the metropolitan areas, due to presence of many pedestrian areas and cobblestones. Therefore, in the center districts, close to the main points of interest, continuous maintenance is needed, but that is not always guaranteed (i.e., tree roots).

Other elements to be considered for a correct evaluation of a city accessibility are "services and experiences".

As big containers, services and experiences include hotels, Bed \&Breakfast hotels, restaurants, tourist excursions and shopping opportunities. In tourist destinations, the first facility to be accessible are accommodations. In Rome, the accessible accommodation offered to visitors - hotels and other facilities are marginal, and mostly linked to luxury hotels. This means that there are no low -cost solutions. In fact, $83.9 \%$ of the 5-star hotels are accessible and 71.9\% of 4-star hotels are accessible. Instead, 3-star hotels and 2-star hotels are accessible only per $37.1 \%$ and $24.6 \%$ respectively. The same situation of scarce accessibility in the 
accommodation supply in Rome is in the $\mathrm{B} \& \mathrm{~B}$, where only the $14.9 \%$ are accessible to everyone (own processes on data from several sources).

Thanks to direct observation and tourist interviews in the center of the city of Rome - the center of the city is defined by the boundaries of the ancient Roman walls. It is estimated that only the $31.6 \%$ of museums and cultural points of interest are accessible; only $7 \%$ of restaurants are fully accessible to every kind of needs, i.e., food intolerance, wheelchair user, and the like, and $18.2 \%$ of shops are accessible.

In Rome, despite the fact that some interventions on accessibility were carried out both on private and public initiatives, there is still a lot of work to be done to guarantee an ability to be competitive with the main European travel destinations.

The lack of accessibility and the obstacles for persons with disabilities, combined with poor customer service and a scarcity of public transportation services, could be substantially reduced by substantial investments by government and corporations. Unfortunately, in the case of Rome, even the "Information and communication" seems not to be sufficiently strong enough to reduce the other obstacles. So, in the construction of an accessible city, information is a first point to be considered. In fact, it is an easy way to reduce barriers and it is not requiring high investments of capital. Providing complete and reliable information on the accessible facilities and services that enable tourist to avoid the hazards and pitfalls associated with travel can reap huge dividends in the longer term! Positive information is a good way to start the construction of an accessible destination (Shaw \& Coles, 2004). But, it is not easy! In fact, there is still no complete mapping of structures and services; and no clear and uniform information about data in the different destinations.

Greater attention must be paid to the problem of mobility. It must be provided in a range of public transport and proper equipment for all the needs such as hand rails and ramps (Darcy, 2002). To improve progressively urban accessibility, it is necessary to carry out interventions aimed at eliminating architectural barriers.

Many people are skeptical about the advantages of accessible tourism, in Rome and in other areas of Italy and Europe.

This narrow-minded vision is a barrier for the development of the local economies and to the creation of the accessibility.

\section{Conclusion}

Accessibility is one of the quality factors of a more articulated and complex proposal. The competitive advantages of the companies are realized when intangible resources are valued, contemplating the interests of consumers with the company's ability to meet the needs of market and profits (Brogna, Cocco, 2015). Therefore, building an accessible offer is part of the possible strategies of responsible business, because it allows people with special needs to be able to meet on the market tourism appropriate quality proposals to their needs and desires.

Considering, therefore, the strong impact generated by the accessible tourism sector, it is clear that people with disabilities and the elderly people represent a very significant segment (Miller \& Kirk, 2002). So, potential demand is constantly growing.

To understand the advantages and criticalities of the accessible tourism offer in Rome, it is important to understand how a city is ready to compete with the "European sisters" and to ensure a varied offer of tourism 
for all. The inaccessible offer of Rome is a money-losing factor, estimated to be in the range of billions of euros far into future years!

The destination's competitiveness seems to be linked to the ability to provide goods and services better than other destinations (Dwyer, Forsyth \& Rao, 2000). Thus, it is evident that accessible tourism is not only a necessity, but also an enormous business opportunity.

Intelligent management of the accessible tourist destination will enable the increased flow of tourism into Rome and the surrounding territory, thus, creating more employment in the sector (Daniels, Rodgers, Wiggins, 2005). That would lead the city to be more competitive in the tourism industry than other European capitals. Accessibility no longer becomes an accessory requirement, but rather a fundamental element in the development of tourism. In this sense, accessibility will create a competitive advantage and an incentive for the development of all of Rome's local economies. It is an enrichment, due to the ability to create useful services for everyone.

Tourism competitiveness includes prices and productivity levels of various components of qualitative factors that increase the attractiveness of a destination (Dwyer, 2005). Accessibility is a keyword to ensuring comfortable and safe services for citizens and businesses, in other words it is a synonym for quality and will mean the same price, same location but more tourists, and therefore, a substantial increase in Rome's multi-million Euro tourist industry.

\section{References}

Aa. Vv. (2009) Le dinamiche del mercato turistico: impatto della crisi economica internazionale ed esigenze di innovazione. RapportoUnioncamere. Rimini: Maggioli

Aslaksen, F., Bergh, S., Bringa, O. R., Heggem, E. K. (1997). Universal design: Planning and design for all. Norway: The Norwegian State Council on Disability.

Brogna, M. (2015), Turismo poliedrico. Un brainstorming sulle nuove opportunità di sviluppo turistico. Roma: Sapienza Editrice.

Brogna, M., Cocco, V. (2015). “Turismo accessibile”. In Turismo poliedrico. Un brainstorming sulle nuove opportunità di sviluppo turistico, Edited by: Brogna, M., 31 -80. Roma: Sapienza Editrice.

Buhalis, D., Darcy, S., Ambrose, I. (2005). Best practice in accessible tourism. Bristol: Channel View Publications. Buhalis, D., Michopoulou, E., Eichhorn, V., Miller, G. (2005). Accessibility market and stakeholder analysis: One-stop-shop for accessible tourism in Europe (OSSATE). UK: University of Surrey.

Buono, S., Zagara, T. (2003). ICF classificazione internazionale del funzionamento, della disabilità e della salute, ciclo ev olutivo e disabilità, Life span and disability, Vol. 6, no 1, 121-141.

Burnett, J. J. and Bender Baker, H. (2001). Assessing the travel-related behaviors of the mobility-disabled consumer, Journal of Travel Research, Vol. 40, no 1, 4-11.

Cocco, V., EmbertiGialloreti, U. (2016). "Turismo accessibile". In Il turismo a Roma. Per crescere tutti. Per crescere assieme, Edited by: Celant, A., Misischia, M., 47 - 57. Roma: MarchesiEditore.

Daniels, J.M., Rodgers, E., Wiggins, B. (2005). Travel tales': an interpretative analy sis of constraints and negotiations to pleasure travel as experiences by person with physical disabilities, Tourism management, Vol. 26, no 1, 919-930.

Darcy, S. (2002). Marginalized participation: Physical disability, high support needs and tourism, Journal of Hospitality and Tourism Management, Vol. 9, no 1, 61-72.

Darcy, S. and Dickson, T. (2009). A whole-of-life approach to tourism: The case for accessible tourism experiences, Journal of Hospitality and Tourism Management, Vol. 16, no 1, 32-44.

Del Zanna, G. (1995). Uomo, disabilità, ambiente, ricerca dei criteri per una progettazione accessibile. Milano: Editriceabitare. Dredge, D., Jenkins, J. (2003). Destination place identity and regional tourism policy, Tourism Geographies, Vol. 5, no 4, $383-407$.

Dwy er, L. (2005). “Trends underpinning global tourism in the comingdecade”. In Global tourism, Edited by: Theobal, W. 529-545. Burlington: Butterworth Heinemann. 
Dwyer, L., Forsyth, P., Rao, P. (2000). The Price Competitiveness of Travel and Tourism: A Comparison of 19 Destinations, Tourism Management, Vol. 21, no 1, pp.9-22.

Eichhorn, V., Buhalis, D. (2007). The accessibility requiring market in Europe: Socially and economically important, e-Review of Tourism Research, Vol. 5, no 2, 34-36.

English Tourism Council. (2000). People with disabilities and holiday taking. London: English Tourist Council.

European Commission (2013). "Economic impact and travel patterns of accessible tourism in Europe - Final report" Service Contract SI2.ACPROCE052481700 - European Commission, DG Enterprise and Industry

Miller, G. A., Kirk, E. (2002). The disability discrimination act: Time for the stick, Journal of Sustainable Tourism, Vol. 10, no 1, $82-88$.

Picone, R. (2004). Conservazione e accessibilità. Il superamento delle barriere architettoniche negli edifici e nei siti storici. Napoli: arte tipograficaeditrice.

Rota, G., Rusconi, G. (1996). Barriere architettoniche.Milano: Il sole.

Shaw, G., Coles, T. (2004). Disability, holiday making and the tourism industry in the UK: a preliminary survey, Elsevier, Vol 25, no 3, 397-403. 